\title{
Microbial IC50 Reference Control Result
}

National Cancer Institute

\section{Source}

National Cancer Institute. Microbial IC50 Reference Control Result. NCI Thesaurus. Code C139120.

A reference control sample response based on the concentration of a specific drug expected to produce 50 percent inhibition on the enzymatic activity of a microbial organism. 